\title{
Avaliação dos efeitos inflamatório e oxidante do ozônio medicinal em articulações sinoviais de equinos hígidos
}

Cynthia do Prado Vendrusculo; Juliana Junqueira Moreira, Sarah Raphaela Torquato Seidel, Joice Fülber, Henrique Macedo Neuenschwander, Fernanda Rodrigues Agreste, Raquel Yvonne Arantes Baccarin

Faculdade de Medicina Veterinária e Zootecnia, Universidade de São Paulo (USP), São Paulo, SP, Brasil

*Autor correspondente

e-mail: cpvendruscolo@usp.br

\section{Resumo}

A ozonioterapia consiste na aplicação de ozônio medicinal, mistura de ozônio e oxigênio $\left(\mathrm{O}_{2}\right)$ que, por meio das espécies reativas de oxigênio e produtos de lipoperoxidação, exerce diversos efeitos no organismo como melhora da oxigenação e metabolismo dos tecidos, angiogênese, aumento dos mecanismos antioxidantes, melhora do sistema imune, efeito anti-inflamatório, entre outros. Esta modalidade terapêutica já é amplamente estudada na medicina humana e vem sendo aplicada na medicina esportiva equina no tratamento de osteoartrite, porém sem estudos expressivos que comprovem sua segurança e eficácia. 0 objetivo deste estudo foi analisar os efeitos inflamatório e oxidante do ozônio medicinal em articulações sinoviais de equinos hígidos. Foram utilizadas 24 articulações tibiotársicas distribuídas aleatoriamente em três grupos. Os grupos tratados receberam três aplicações semanais de $15 \mathrm{ml}$ de ozônio medicinal na concentração de 20 (GA) e $40 \mu \mathrm{g} / \mathrm{ml}$ (GB), totalizando 10 aplicações. Já no grupo controle, as articulações receberam três aplicações semanais de $15 \mathrm{ml}$ de $\mathrm{O}_{2}$ (GC), também no total de 10 aplicações. Foram realizados exames físico, de claudicação, com o aparelho Lameness Locator $^{\circledR}$ e ultrassonográfico. Líquido sinovial (LS) foi coletado para realização da contagem total de células nucleadas e quantificação de proteína total, prostaglandina E2, Substância P, interleucina-1, interleucina-6, interleucina-10, fator de necrose tumoral- $\alpha$, condroitim sulfato e ácido hialurônico (concentração e peso molecular). A atividade da superóxido desmutase (SOD) e o burst oxidativo foram determinados para avaliar o potencial antioxidante. Houve aumento de temperatura em ambos os grupos tratados. Os animais de GB apresentaram claudicação mais intensa em relação aos demais grupos, provavelmente devido a maior dose de $\mathrm{O}_{3}$ utilizada. Aumento dos escores ultrassonográficos ocorreu em todos os grupos, mas diminuíram rapidamente em GA, provavelmente devido a menor concentração de $\mathrm{O}_{3}$ aplicada. Em relação ao GC, a contagem celular do LS aumentou tanto em GA quanto em GB, sendo 
observado maior porcentual de polimorfonucleares em GB. Houve aumento da concentração de proteína em ambos os grupos tratados, provavelmente devido à vasodilatação ocasionada pelo $\mathrm{O}_{3}$. Maior atividade da SOD e do índice de ativação foram observados em GA, corroborando com a literatura que o $\mathrm{O}_{3}$ na dosagem $20 \mu \mathrm{g} / \mathrm{ml}$ aumenta a capacidade antioxidante articular e promove maior ativação dos neutrófilos. A concentração de ácido hialurônico diminuiu em todos os grupos, mas não houve alteração significativa no tamanho da molécula. As concentrações de condroitim sulfato diminuíram nos grupos GB e GC. Não houve diferença nas concentrações de PGE2, substância P, IL-1, IL-6, IL-10 e TNF- $\alpha$. Conclui-se que a aplicação intra-articular de ozônio medicinal em equinos é segura em ambas as doses e que experimentos devem ser realizados utilizando animais com diferentes doenças articulares, para que os benefícios da ozonioterapia sejam evidenciados e compreendidos.

Palavras-chave: Cavalo. Interleucina. Líquido sinovial. 